indigenous Lepidoptera the appearance of which is to be recorded, and three immigrants. This has been at the expense of a considerable reduction in the bird migration list, as many of those subjects had been reported on continuously for many years. There has been an extension in the selected observations on trees, chiefly in regard to leafing times. The modern system of Latin bird names is now used, although observers are warned that the old system is still used in some reference books. Particular stress is laid on the importance of recording the effects of abnormal weather upon the vegetation, etc. Spring and early summer appearance dates of the peacock and red admiral butterflies should help gather additional information regarding the question of their hibernation. A valuable addition to the recording of flowering of plants and leafing of trees is the recording, as well as the date, of the sheltered or open position of the plant. On the whole, the amount of observation called for has been considerably increased, but individual phenologists are encouraged to send in returns of any one group if they wish.

\section{Norman Lockyer Observatory}

Bulletin No. 2 of the Norman Lockyer Observatory, Sidmouth, recently issued, contains an appreciation of the late Sir Robert Mond, chairman of the Observatory Corporation for twenty-one years and a generous benefactor to the Observatory. A further note of a personal nature gives an account of the unveiling of the memorial to the late director, Dr. W. J. S. Lockyer, at which Sir Robert Mond presided just three months before his death. Part of the memorial alluded to is the Oxford microphotometer, a description of which is given in the present Bulletin by the director, Mr. D. L. Edwards, together with illustrations of representative tracings of stellar spectra and of several line-contours, obtained with the instrument. Mr. D. R. Barber contributes two papers. The first is a detailed account of the magnificent auroral display of January 25, 1938, which appears to have been visible over practically the whole of Europe and the North American continent. The second paper deals with the objective prism-spectra of Finsler's Comet obtained at its apparition of 1937. In a preliminary investigation (N.L.O. Bull., No. 1), Barber had found that a visual comparison of the intensities of the cometary bands at 4700 and $3880 \mathrm{~A}$. due to $\mathrm{C}(I V)$ and $\mathrm{CN}(I V)$ radiation respectively indicated that the former was about $2 \frac{1}{2}$ times stronger than the latter, a result in the opposite direction from that deduced from slit spectrograms secured at the Mt. Wilson and the Lick Observatories. The Sidmouth spectrograms have now been analysed by means of the new microphotometer, and Barker confirms his first result with, however, a reduction of the ratio of relative intensities from $2 \frac{1}{2}: 1$ to $1 \frac{1}{4}: 1$.

\section{Literature for Adult Education}

AN important factor in the success of discussion groups or public lectures as a means of education for citizenship is the provision of books and other suitable material for reading. A pamphlet, "Printed Page and the Public Platform", which has recently been issued by the Office of Education, United States Department of the Interior (Washington, D.C. : Gov. Printing Office, 20 cents), analyses the different factors involved and gives an account of experiments and experience in the United States which should be highly useful to those interested in adult education in Great Britain. The necessity for close co-operation between libraries and such discussion groups is emphasized, and a number of practical suggestions are detailed to facilitate co-operation. The scope and functions of reading lists are critically discussed and the importance of having the reading material as accessible as possible to those taking part in the discussions or attending lectures is recognized. Equally important is the suitability of the material, and while the criticism is not specifically directed at scientific literature, it applies equally to that intended for the general public. Able exposition is a first condition of success, involving an understanding not only of the subject handled but also of the readers to whom the book or article is addressed, and if pamphlet literature admittedly presents special difficulties, the problem is one which deserves greater attention because of its greater appeal to many readers in spite of the distribution difficulty.

\section{The International Seismological Summary}

The I.S.S., compiled at Oxford, is a work which increases in volume and range as it progresses. The volume for January, February and March 1933, which commences the sixteenth volume, has just appeared, and deals with 165 epicentres, 67 being new and 98 repetitions from old epicentres. Nine of the earthquakes mentioned have foci which are below normal. The epicentres have, in general, been determined from observations of $P$ alone, instead of by the old method of using $S-P$ differences. This is said to make very little difference in the case of well-observed earthquakes, but is greatly to be preferred on theoretical grounds. During the last five years, the range of numbers of earthquakes with determinable epicentres recorded in the I.S.S. has been from 569 in 1932 to 653 in 1930 . It appears, therefore, that notwithstanding the greater number of stations sending readings, and the greatly improved registration, the numbers of such earthquakes have reached a probable limit. In this volume, stations which send additional readings to the usual $P, S, L$ and $M$ are thanked especially, and for the future all are requested to classify wherever possible their $L$ readings into $L Q$ and $L R$, and to state whether the initial $P$ reading is compressional or dilatational.

\section{The Medical Press and Circular}

The issue of January 25 of the Medical Press and Circular is a centenary double number. This journal is, as the name suggests, the combination of two, namely, the Dublin Medical Press, founded in Dublin in 1839, and the Medical Circular, founded in London in 1852, the union taking place in 1866. Prof. Rowlette of Dublin contributes a short history of the journal during the hundred years, with biographical 